\title{
Desafios e estratégias na construção de biografias de escravos: o caso dos rebeldes envolvidos no plano de insurreição de Campinas (1832)
}

Challenges and strategies in the process of writing slave biographies: the case of the rebels involved in Campinas uprising plan (1832)

\author{
Ricardo Pirola ${ }^{1}$
}

ricardopirola@yahoo.com

\section{Resumo}

O objetivo deste artigo é analisar as questões que envolvem a pesquisa e a narrativa de biografias de escravos e forros, tomando como ponto de partida o estudo de um plano de insurreição, descoberto na cidade de Campinas no ano de 1832. A intenção é destacar os desafios que implicam a construção de trajetórias de "gente comum" e ainda algumas das estratégias que podem ser adotadas. Chamaremos a atenção para o método de ligação nominativa de fontes e para a análise quantitativa dos dados como possíveis caminhos para a elaboração dessas biografias.

Palavras-chave: Biografias de escravos; Rebeldia escrava; História de Campinas.

\begin{abstract}
The purpose of this article is analyze the issues surrounding the research and the historical narrative of slave biographies, taking as its starting point the study of a plan for rebellion, discovered in the city of Campinas in 1832. Our intention is to highlight some of the challenges involving the reconstruction of ordinary people trajectories and to present some of the strategies that can be adopted. It is also our purpose to pay attention to the "nominative record linkage" method and to the quantitative analysis as possible ways to write historical biographies of slaves.
\end{abstract}

Keywords: Slaves Biographies; Slave Rebellion; History of Campinas.

1 Professor do Departamento de História da Universidade Estadual de Campinas (SP). Doutor em história pela mesma instituição. Pesquisador do Centro de Pesquisa em História Social da Cultura (Cecult). 
Artigos

A historiografia da escravidão no Brasil nos últimos anos tem se destacado pelo aparecimento de um grande número de trabalhos dedicados a reconstruir biografias de escravos e forros (FURTADO, 2003; FRANK, 2004; GRAHAM, 2005; REIS, 2008; XAVIER, 2008; REIS, GOMES E CARVALHO, 2010; MACHADO, 2010; SWEET, 2011). De fato, esse tipo de pesquisa se tornou uma verdadeira febre acadêmica, com resultados bastante reveladores da sociedade escravista colonial e Imperial. Ligado tradicionalmente a nomes da grande política ou a personagens que ganharam fama nas áreas artísticas, literárias ou científicas, o gênero biográfico, voltado agora para pessoas comuns, aparece como uma importante perspectiva de pesquisa e de narrativa histórica, levantando novas questões a respeito das relações entre o particular e o geral, o público e privado e ainda entre as ações individuais e as intervenções coletivas. O estudo das trajetórias de vida de escravizados e de forros tem colaborado também na ampliação do debate sobre os processos de construção de identidades entre os grupos subalternos (e suas várias conexões atlânticas) e no alargamento do entendimento das estratégias adotadas por tais indivíduos diante dos sistemas de dominação em que estavam inseridos.

Apesar das heterogêneas linhas teóricas que envolvem a produção dos estudos biográficos, autores como Carlo Ginzburg (1987), Natalie Zemon Davis (1987; 1997), Emmanuel Le Roy Ladurie (1997) e Giovanni Levi (2000) desde a década de 1980 tornaram-se referência neste tipo de produção historiográfica. Inspirados nesses autores, cujos métodos consistiam, entre outras coisas, na redução da escala de análise e na pesquisa sistemática em fontes seriais, surgiram diversos trabalhos dedicados aos mundos da escravidão e liberdade no Brasil, que se voltaram especialmente para os arquivos regionais e para a utilização de documentos eclesiásticos (a exemplo dos registros de nascimento, casamento e óbito), cartoriais (tais como os inventários e testamentos), inquisitoriais e judiciários (como no caso dos processos-crime e processos-cível). Outra marca destes trabalhos dedicados à história do Brasil foi a incorporação dos procedimentos de pesquisa na narrativa historiográfica a exemplo do que faz Natalie Davis (1987) em O retorno de Martin Guerre. A intenção dos autores é a de explicitar ao leitor as fontes e métodos utilizados, delineando os contornos de suas conclusões.

Foi justamente inspirado por essas perspectivas de análise que nasceu o livro Senzala Insurgente, no qual elaboro uma biografia coletiva dos 32 escravos e de um liberto acusados de planejarem uma revolta na cidade de Campinas no ano de 1832 (PIROLA, 2011). A partir do processo-crime instaurado para investigar a trama rebelde, recorri a diversos outros documentos a fim de acompanhar a trajetória dos acusados de envolvimento no plano de insurreição. O objetivo agora é revisitar esse caso de 1832, buscando destacar as questões e desafios que envolveram o processo de pesquisa e de narrativa de biografias de escravos e forros. Pretendo, ao mesmo tempo, chamar a atenção para algumas das possibilidades de análise do passado escravista de Campinas, a partir do acervo do Centro de Memória - Unicamp. Com uma coleção de fontes que vai desde documentos cartoriais (inventários, testamentos, registros de transferência de propriedades, alforrias), passando por documentos oriundos do judiciário local (processos-crime e processos-cível) e abrangendo ainda periódicos e registros iconográficos, o Centro de Memória representa um dos arquivos mais importantes para a pesquisa da história da escravidão. O grande destaque, em comparação com outras instituições similares, é o fato de que boa parte de suas séries documentais se encontram completas, podendo ser consultadas por várias décadas seguidas (estando alguns dos seus fundos catalogados digitalmente). De fato, o reconhecimento da qualidade de sua documentação pode ser medido pela grande número de pesquisas já realizadas a partir de seu acervo ${ }^{2}$.

Assim, inicio minhas análises com uma descrição do plano de insurreição de 1832, produzida a partir dos depoimentos de escravos apresentados no processo crime instaurado para investigar a trama, visando em seguida mostrar a maneira pela qual minha pesquisa buscou encarar os desafios impostos pela escrita do gênero biográfico voltada para o estudo de trajetórias de escravos. Buscarei discutir as implicações de se acompanhar as trajetórias dos revoltosos a partir do método de ligação nominativa de fontes e chamarei a atenção para a importância da pesquisa se voltar para a análise serial dos documentos levantados.

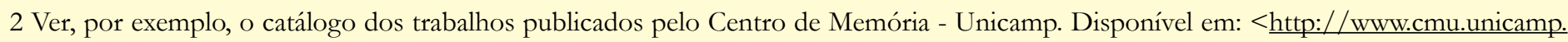
br/publicacoes/catalogo >. Acesso em: 03 maio 2015. 


\section{O processo-crime de 1832 e o plano dos escravos}

Em carta datada de 3 de fevereiro de 1832, o senhor de engenho Antônio Francisco de Andrade relatou ao juiz de paz de Campinas a descoberta de um plano de insurreição escrava. Contou que desde meados do mês de janeiro andava desconfiado do comportamento de seus cativos que já não tinham mais a mesma presteza na execução de tarefas e abandonavam a fazenda durante a noite, apesar de suas repreensões. Disse ainda que suas suspeitas só aumentaram quando seus irmãos e vizinhos de propriedade relataram um comportamento semelhante de suas escravarias. Decidiu então reunir aqueles cativos que lhe pareciam mais propensos a se rebelarem e, por meio de castigos físicos a alguns e promessas de perdão a outros, conseguiu que um deles confessasse. Envolvendo quinze engenhos produtores de cana-de-açúcar e a participação de um liberto conhecido como João Barbeiro, morador da cidade de São Paulo, preparava-se na região de Campinas uma grande rebelião.

O plano de revolta de 1832 estava muito bem organizado em termos de comando e divisão de tarefas. Em cada uma das quinze fazendas envolvidas na trama existia um escravo intitulado "capitão", que tinha a função de convidar outros parceiros para a revolta e também de arrecadar dinheiro para ser investido na compra de armas. Das quinze fazendas, onze estavam localizadas em um mesmo bairro rural de Campinas, facilitando a circulação e o contato entre os escravos. As reuniões dos revoltosos ocorriam sempre durante a noite, mudando de tempos em tempos o local de encontro para evitar a suspeita senhorial.

O escravo apontado como a liderança principal do plano de 1832 era Diogo Rebolo. Chamado de pai pelos revoltosos, Diogo Rebolo era o responsável por comandar todas as reuniões noturnas dos cativos e também por exercer a função de caixa principal do dinheiro arrecadado pelos capitães. As funções de Diogo Rebolo no plano de insurreição, contudo, iam muito além de um líder político ou militar. Segundo os revoltosos, ele era o responsável por preparar uma bebida a base de raízes que servia para fechar o corpo dos escravos durante a revolta e tornar mais lenta a reação senhorial. O escravo Bento, por exemplo, diz em seu testemunho que a bebida servia para "animar, livrar de chumbo e das facas dos brancos". Já o escravo Joaquim comentara que a bebida deixaria lenta a reação senhorial quando tivesse início a rebelião. Bento disse ainda que a bebida ajudava no combate a feitiçaria. As habilidades sobrenaturais do Diogo Rebolo, contudo, não paravam por aí. Nos depoimentos recolhidos no processo-crime, um dos escravos envolvidos na elaboração da trama, revelara que o líder dos rebeldes tinha também a capacidade de fazer adivinhações.

O dinheiro entregue a Diogo Rebolo pelos capitães do plano era enviado ao liberto João Barbeiro em São Paulo, que tinha a função de comprar armas e munições para a revolta. As ligações entre o Diogo Rebolo e João Barbeiro eram feitas por um cativo tropeiro que fazia frequentes viagens para a capital da província, comprando e vendendo mercadorias para seu senhor. A relação entre o liberto e os escravos em Campinas não nasceu, contudo, com o plano de insurreição de 1832. João Barbeiro morou em Campinas até o ano de 1830, quando foi acusado de estar envolvido em outro plano de insurreição escrava. Poucas fontes sobraram para os historiadores de hoje sobre a suspeita de rebelião de 1830, sabemos apenas que o liberto foi acusado de ser um dos principais líderes, sendo por isso mandado para a cadeia em São Paulo. A medida, porém, não foi suficiente para apagar o ímpeto revolucionário do liberto. João Barbeiro fugiu da prisão e restabeleceu contatos com os cativos do interior. Não chegou a voltar para Campinas, mas sabemos que, além de estar envolvido na organização da revolta de 1832, o liberto também ajudava a esconder escravos fugidos. As ligações de João Barbeiro com a população escravizada tornavam real um dos piores pesadelos senhoriais, a união de escravos e libertos.

As investigações do plano de 1832 revelaram ainda que a obtenção de armas para a revolta não era tarefa exclusiva de João Barbeiro. Segundo o depoimento dos revoltosos, o escravo Benedito Ferreiro fabricou lanças de ferro para a utilização durante a revolta. Apesar do escravo ferreiro ter negado essa acusação, provavelmente com o intuito de evitar uma condenação mais severa, o fato é que muitos cativos confessaram já terem suas próprias lanças e armas prontas para a insurreição.

A data prevista para o inicio da rebelião era o dia 22 de Abril de 1832, domingo de Páscoa, uma das mais importantes festas religiosas no Brasil do século XIX. O início da revolta coincidindo com feriados religiosos não é uma particularidade do caso campineiro. Estudos sobre as insurreições escravas no Brasil 
Artigos

têm mostrado que os dias santos eram os que mais frequentemente registravam levantes de escravos. Nessas datas, os cativos eram dispensados de suas funções nas propriedades senhoriais e aproveitavam o momento para trabalhar em suas próprias roças ou para participar das celebrações locais. Também os senhores costumavam se dirigir à igreja matriz da cidade, onde ouviam a missa e participavam das festividades organizadas pela comunidade. Tratava-se, portanto, de um momento de menor vigilância senhorial nos engenhos e de folga dos escravos.

As investigações mostraram também que o liberto João Barbeiro convidara outros escravos moradores da cidade de São Paulo para se juntarem ao levante. Na véspera da insurreição, João Barbeiro e os cativos arregimentados na capital percorreriam o trajeto entre as duas localidades durante a noite para não despertar a desconfiança das autoridades. Chegando a Campinas, eles se juntariam aos demais revoltosos para iniciar a rebelião. Para infelicidade dos escravos, porém, nem tudo saiu como o esperado, o comportamento de alguns dos envolvidos acabou despertando a atenção senhorial e levou à descoberta da trama de 1832.

\section{Biografias de escravos: questões e métodos de análise}

Suely Robles Reis de Queirós (1977) em a Escravidão negra em São Paulo foi a primeira autora a chamar a atenção para o projeto de insurreição de 1832 em Campinas. Utilizando o processo-crime e a correspondência trocada entre as autoridades do interior e da capital, Queirós interpretou a trama como uma das reações dos cativos diante do sistema repressor montado pelos senhores. Interessava à autora mostrar a rigidez do modelo escravista no Brasil e as respostas violentas dos escravos, em contraponto às teses ainda presentes em diversos trabalhos sobre o caráter ameno da escravidão em nosso país (especialmente quando comparada com os Estados Unidos). Se, por um lado, as análises de Queirós desempenharam um papel fundamental no debate sobre as características do escravismo no Brasil, por outro, ainda se mostrava necessário avançar na compreensão da organização do plano de insurreição e das relações estabelecidas entre os cativos das 15 propriedades que dele participaram. Nesse sentido, a análise das trajetórias dos escravos rebeldes antes do envolvimento na trama de 1832 se apresentava como uma possibilidade de avançar nessas questões. Assim, ao me centrar no estudo das trajetórias dos escravos ao longo das três primeiras décadas do oitocentos, busquei perceber quais elementos estiveram presentes na base das relações sociais que deram origem ao plano.

Uma das questões fundamentais que envolvem o trabalho de construção de biografias de escravos e forros se relaciona com o fato de não encontrarmos fontes que nos permitam acompanhar suas trajetórias por vários anos seguidos (como é o caso, por exemplo, de livros de memórias ou diários que contam a trajetória de indivíduos livres). Os documentos que nos foram legados sobre a escravidão geralmente revelam momentos específicos das vidas dos cativos como, por exemplo, a época em que um determinado escravo conquistou a alforria (registrado em documentos como cartas de alforria, testamentos, registros de batismos), a período do casamento na Igreja (registrado nos livros paroquiais) ou mesmo o momento de uma ação diante da Justiça, seja como réu ou como vítima (resultado, por exemplo, de participação em um determinado crime ou pela representação em uma ação de liberdade). No caso dos envolvidos no plano de insurreição de 1832, por exemplo, nossa primeira imagem registrava suas ações na organização da trama, mas pouco se podia saber de suas trajetórias anteriores.

Para tentar contornar esses desafios e recuperar a trajetória dos rebeldes antes de se envolverem na revolta foi importante a adoção de duas estratégias simultâneas: 1) recorrer a uma série variada de documentos, a exemplo dos registros eclesiásticos, dos censos populacionais e dos inventários em busca de localizar os réus indiciados no processo-crime em diferentes momentos de suas vidas (por meio de um processo de ligação nominativa de fontes); 2) buscar reconstruir o ambiente em que os biografados estavam inseridos. Isto é, interessava conhecer o contexto mais amplo que os envolvia, a fim de entender suas particularidades em meio a outros escravos e forros que moravam em Campinas no mesmo período. Para melhor delinear tais caminhos percorridos pelo trabalho, passo a explicar detalhadamente esses dois pontos.

No que se refere ao processo de ligação nominativa de fontes, a primeira tarefa foi a de construir uma lista com o nome do liberto indiciado, dos 32 escravos e de seus respectivos senhores, para tentar encontralos em outros documentos. O fato dos escravos não terem sobrenome tornava essencial começar a busca 
sobre suas trajetórias a partir dos nomes de seus senhores. Assim, o processo-crime de 1832 se transformou no ponto de início do trabalho, uma vez que permitia obter as primeiras informações sobre os personagens a serem biografados. Nesse momento foi criada uma ficha para cada um dos envolvidos no plano de revolta com os dados sobre o papel por eles desempenhado na trama e o nome dos seus respectivos senhores. Com essas fichas em mãos, voltei-me, inicialmente, para os inventários post-mortem dos proprietários da cidade de Campinas no século XIX, que se encontram guardados no Centro de Memória - Unicamp. Ao arrolar todos os bens pertencentes a um determinado indivíduo, os inventários incluíam, é claro, os escravos (que geralmente eram os pertences mais valiosos encontrados nesse tipo de documentação). As listas de escravos presentes em tais fontes apresentam informações importantes como o nome, a idade, descrições gerais da saúde, preço e, por vezes, as relações de parentesco existente entre os cativos. Ou seja, os inventários representavam um valioso documento para o trabalho de levantamento de dados sobre rebeldes de 1832.

A primeira dificuldade ligada à pesquisa com os inventários, porém, se relacionou com o fato de que muitos senhores que tiveram cativos envolvidos no plano de insurreição faleceram muitos anos depois de 1832 (o que não nos dava informações sobre a trajetória dos cativos anterior à revolta, nem possibilitava entender a própria configuração das fazendas em que eles moravam no momento de organização da trama rebelde $)^{3}$. Dessa maneira, foi necessário ampliar o escopo analítico da pesquisa para incluir os cônjuges dos senhores com escravos mencionados no processo-crime, recorrendo às genealogias e aos catálogos de fontes do Centro de Memória - Unicamp, com o objetivo de identificar seus nomes. Foi dessa forma, por exemplo, que conseguimos localizar o inventário de Dona Paula Joaquina Andrade, esposa de Floriano de Camargo Penteado (proprietário que mais teve cativos envolvidos no projeto de insurreição). Dona Paula faleceu em 1830, o que levou à feitura de seu inventário naquele mesmo ano com a descrição de todos os bens pertencentes a ela e ao marido (a legislação previa que metade dos bens de um casal deveria ficar com o cônjuge vivo e a outra metade era repartida entre os herdeiros). Essa fonte nos permitiu identificar diversos cativos envolvidos no plano de insurreição, nos dando uma visão de suas trajetórias momentos antes de 1832 . O mesmo procedimento adotado na localização do inventário de Dona Paula Joaquina Andrade foi repetido com outros proprietários, favorecendo a identificação de mais 2 documentos. Ao final, foi possível juntar esses vários fragmentos de informações na composição da biografia dos rebeldes de 1832 .

A segunda série documental pesquisada foi o censo populacional da cidade de Campinas para as três primeiras décadas do oitocentos ${ }^{4}$. Produzidos quase que anualmente entre 1767 e 1829, os censos populacionais registravam o nome, idade e condição matrimonial tanto de livres quanto de escravos. Novamente, a maneira de localizar os escravos envolvidos na trama rebelde de 1832 nesse tipo de fonte se dava por meio dos nomes dos seus proprietários. Por exemplo, a localização do Diogo Rebolo, a principal liderança do plano de insurreição em Campinas, no censo populacional, passou inicialmente pela identificação de seu senhor nessa documentação, chamado Joaquim José dos Santos. Assim, percorri as diversas páginas do levantamento de 1829 (censo mais próximo da data do plano de revolta) até encontrar o nome de Joaquim José dos Santos. Ao encontrá-lo, pude então acessar as informações sobre os seus escravos naquele mesmo ano. O trabalho foi repetido para os anos anteriores, retornando ao período em que esse senhor apareceu pela primeira vez no censo populacional de Campinas (1804). Assim, ao seguir ano após ano os passos de Joaquim José dos Santos no censo local, pude perceber as transformações que o tempo imprimiu em sua vida e na dos seus escravos ao longo das primeiras décadas do século XIX. Todas essas informações, cruzadas ainda com os dados encontrados no processocrime e nos inventários, colaboraram para ampliar minhas informações sobre os rebeldes de 1832.

Por fim, a terceira fonte utilizada de maneira sistemática em busca dos escravos rebeldes foram os registros eclesiásticos ${ }^{5}$. O trabalho com esses documentos se baseou no ato de rastrear os nomes dos cativos envolvidos no projeto de insurreição nos livros de casamento e nascimento da Igreja Matriz de Campinas para as três primeiras décadas do oitocentos. A pesquisa com esse tipo de fonte teve que ser ampliada con-

3 Os inventários de Campinas do século XIX estão guardados no Centro de Memória - Unicamp.

4 Os censos populacionais de Campinas estão guardados no Arquivo do Estado de São Paulo. O Arquivo Edgar Leuenroth possui cópia em microfilme dessa documentação (ver Fundo Peter Eisenberg)

5 Os registros eclesiásticos ficam guardados no arquivo da Igreja Matriz de Campinas. O Arquivo Edgar Leuenroth possui cópia em microfilme dessa documentação (ver Fundo Peter Eisenberg). 
Artigos

forme identifiquei que alguns dos escravos rebeldes eram casados e tinham filhos, me levando a buscar dados sobre esses indivíduos. No que se refere aos escravos crioulos, a tarefa envolveu também o levantamento de informações sobre seus pais e irmãos. Um dos principais desafios envolvendo esse trabalho de acompanhar certos nomes ao longo do tempo utilizando essa documentação relacionou-se ao fato de, frequentemente, um mesmo senhor possuir mais de um escravo com o mesmo nome. Floriano de Camargo Penteado, por exemplo, teve 5 escravos chamados Antônio ao longo das primeiras décadas do século XIX. Nessas situações, o acúmulo de outras informações sobre os biografados, retiradas das fontes indicadas acima, permitia, por vezes, identificar qual dos "Antônios" encontrados nos registros eclesiásticos era aquele que se envolvera na revolta de 1832. Em certas ocasiões, entretanto, a coincidência das informações impedia a identificação dos biografados. De qualquer maneira, para a grande maioria dos casos, foi possível levantar uma gama grande de dados, que foram analisados para conseguir flashes valiosos das trajetórias dos revoltosos de 1832.

Para exemplificar o método de ligação nominativa de fontes e o tipo de informações possíveis de serem identificadas, descrevo um pouco da trajetória Diogo Rebolo. O principal líder da revolta de 1832 foi também um dos primeiros cativos a desembarcar em Campinas. Chegou nessas terras no ano de 1811 e foi mandado para a fazenda de Joaquim José dos Santos ${ }^{6}$. Lá passou a conviver, em meio à produção do açúcar, com mais vinte escravos, quase todos africanos como ele. Desde muito cedo, Diogo Rebolo percebeu como a alta proporção de homens nas senzalas (característica fundamental do tráfico atlântico) interferia diretamente na existência de famílias escravas. Naquele ano de 1811, por exemplo, existiam apenas 3 casais na fazenda, sendo um deles formado pelos cativos Joana e José. Com a morte de José, ocorrida anos mais tarde, a escrava Joana viria a se juntar a Diogo Rebolo. Mas não nos antecipemos.

O casal Joana e José chegou em Campinas no ano de 1804, quando Joaquim José dos Santos, natural de Cotia, migrou para a região a fim de fazer riqueza com o açúcar7. Logo no ano de 1806, Joana registrou na Igreja da Nossa Senhora da Conceição o batismo de seu primeiro filho, o crioulinho Luís. Os padrinhos foram João dos Santos e Dona Maria Francisca Gouveia - parentes de Joaquim José dos Santos e pessoas com importante prestígio social, a julgar pelo título de Dona ${ }^{8}$. Alguns anos mais tarde, quando Luís já tinha quatro anos de idade, a união de José e Joana foi oficializada na igreja da cidade. A cerimônia ocorreu em 5 de agosto de 1810, tendo como testemunhas dois homens livres, Lourenço Soares e João Gomes. O casal permaneceu unido e junto ao pequeno Luís até o ano de 1814, quando, então, o escravo José veio a falecer. Não sabemos ao certo qual foi a causa da sua morte, mas, nessa data, ele era ainda relativamente novo, tendo perto de 25 anos de idade ${ }^{10}$.

Viúva e com o pequeno Luís ao seu lado, Joana continuou lutando e trabalhando para a sua sobrevivência e também para a do seu filho. Não estava sozinha, é claro. Tinha outros escravos e escravas com quem partilhava as agruras da escravidão. Porém, a ausência de um companheiro mais próximo para enfrentar o dia a dia não durou muito tempo. A partir de 1817, o censo populacional começa a indicar que Joana e Diogo Rebolo haviam se unido. O resultado dessa união logo se refletiu nos registros de batismo da igreja local. Diogo e Joana tiveram, ao todo, três crianças batizadas na matriz da cidade: Ignácia, nascida no ano de 1819, sendo padrinhos Joaquim e Maria, escravos de Luís Antônio de Souza; José, em 1824, tendo como padrinho o escravo Joaquim, pertencente a Antônio da Rocha, e madrinha a escrava Maria, do famoso Regente Diogo Antônio Feijó; por último, Maximiano, sendo padrinhos os escravos Salvador e Thereza, de Joaquim José Teixeira. ${ }^{1}$

Foi possível perceber ainda, por meio dos registros de batismo, que Diogo Rebolo e Joana apadri-

6 Censo Populacional de Campinas, Lista de escravos de Joaquim José dos Santos, 1811, Arquivo Edgar Leuenroth (AEL), Fundo Peter Eisenberg (FPE), rolo 1.3, $2^{\text {a }}$ companhia, número 54.

7 Censo Populacional de Campinas, Lista de escravos de Joaquim José dos Santos, 1804, AEL, FPE, rolo 2.3, $1^{\mathrm{a}}$ companhia, número 36.

8 Registro de batismo do escravo Caetano na igreja de Nossa Senhora da Conceição das Campinas, 21 set. 1806, AEL, FPE, rolo 18.

9 Registro de casamento dos escravos José e Joana na igreja de Nossa Senhora da Conceição das Campinas, 05 ago. 1810 , AEL, FPE, rolo 37 , livro 2, folha $55 \mathrm{v}$.

10 Censo Populacional de Campinas, Lista de escravos de Joaquim José dos Santos, 1814, AEL, FPE, rolo 1.2, $2^{\mathrm{a}}$ companhia, número 3.

11 Registro de batismo da escrava Ignácia na igreja de Nossa Senhora da Conceição das Campinas, 23 maio 1819, AEL, FPE, rolo 18. Registro de batismo do escravo José na igreja de Nossa Senhora da Conceição das Campinas, 26 ago. 1824, AEL, FPE, rolo 18. Registro de batismo do escravo Maximiano na igreja de Nossa Senhora da Conceição das Campinas, 15 jul. 1827, AEL, FPE, rolo 18. 
nharam os filhos de alguns de seus parceiros de escravidão. No ano de 1830, por exemplo, o casal batizou a crioulinha Lucrécia, filha de Felizardo e Luzia. ${ }^{12}$ Também identifiquei que Joana batizou ainda outra criança no ano de 1809, quando era casada com o José. Nesse caso, a mãe era a escrava Mariana e o pai incógnito. ${ }^{13}$ No ano de 1829, Diogo Rebolo e Joana ainda são identificados juntos, um após o outro, no censo populacional da cidade. Consegui perceber também que praticamente todos os seus filhos estavam morando na mesma propriedade, à exceção apenas da jovem Inácia, a primeira filha do casal, que nunca chegou a ser registrada nessa documentação. Podemos dizer, todavia, que o pai Diogo Rebolo, como era chamado pelos seus parceiros conspiradores do plano de revolta de 1832, estabeleceu importantes laços de parentesco e companheirismo antes de liderar a conspiração.

Assim, se, por um lado, o método de ligação nominativa de fontes nos permite conhecer vários aspectos da trajetória dos rebeldes de 1832, por outro, ele ganha maior densidade quando inserimos os dados dos biografados dentro de um contexto maior. Nesse sentido, ao analisar os inventários, censos populacionais e registros paroquiais não me interessei apenas em olhar para os escravos citados no plano de insurreição, mas conhecer também as características dos demais que viveram em Campinas na mesma época. Tal estratégia me parecia fundamental para conseguir delinear melhor quem eram os cativos rebeldes, buscando entender que elementos os tornavam semelhantes aos demais escravos e quais atributos os singularizavam. Nesse sentido, em todas as fontes pesquisadas, procurei desenvolver uma análise estatística de seus dados, a fim de cruzar com as informações individuais dos biografados. E é justamente sobre essa segunda estratégia adotada pela minha pesquisa (a de tentar reconstruir o cenário em que viveram os revoltosos de 1832) que passo a analisar a partir de agora.

Com relação aos inventários post-mortem, por exemplo, além de localizar aqueles documentos específicos que pertenciam aos senhores e seus respectivos cônjuges com escravos envolvidos na trama de 1832, realizei ainda um levantamento sistemático desse tipo de fonte para os anos compreendidos entre 1800 até 1835. A intenção foi a de conhecer um pouco mais do perfil demográfico dos escravos que moravam em Campinas, sempre atento a informações como a proporção de homens e mulheres, suas idades e origens. Além disso, interessava conhecer a distribuição da propriedade em escravos entre os livres e suas alterações ao longo do tempo. Esse tipo de análise me permitiu acompanhar, por exemplo, o processo de concentração de cativos nas mãos de um número reduzido de senhores em Campinas e flagrar o florescimento de proprietários que passaram a ter mais de uma centena de escravos, a exemplo do próprio Floriano de Camargo Penteado. Do ponto de vista dos escravos, por sua vez, essa pesquisa favoreceu a percepção de que todo esse processo resultou na formação de senzalas cada vez mais afastadas do controle exercido diretamente pela figura senhorial, no qual a ideologia paternalista poderia ser sentida de maneira próxima. No final do século XVIII, 100\% dos cativos em Campinas moravam em propriedades com menos de 10 escravos; já no começo da década de 1830, cerca de 50\% dos escravos de todo o município vivia em fazendas com 50 ou mais escravos (PIROLA, 2011, p. 60-61). Ou seja, quanto mais crescia e se concentrava a população escrava em Campinas, mais os cativos (nas grandes fazendas) passavam a ficar distantes do contato direto com os senhores, sendo governados por feitores e administradores. Um dos resultados desse processo foi o reforço das próprias ligações e relações horizontais entre os cativos.

Outro elemento que a análise sistemática de todos os inventários abertos em Campinas nas três primeiras décadas do oitocentos me permitiu saber se relaciona com a origem dos cativos. Em primeiro lugar, foi possível perceber o processo de africanização dos escravos nessa região. Se no ano de 1801 os africanos representavam por volta de 50\% dos escravizados em Campinas, em 1835 eles compreendiam 70\% do total. A alta proporção de africanos também se repete no próprio plano de insurreição, fazendo com que $90 \%$ dos rebelados indiciados fossem provenientes do outro lado do atlântico. Os inventários nos permitiram avançar também na questão das origens africanas dos cativos, favorecendo análises sobre as procedências daqueles que para cá vieram nas primeiras décadas do oitocentos. Assim, se no começo do século XIX o predomínio era de africanos provenientes do sul Angola, chamados por aqui de Benguelas, na década de 1830 a preponderância passou a ser de escravos provenientes do norte de Angola e do Congo norte. É curioso perceber como as origens dos envolvidos no plano de insurreição acompanharam tais mudanças, sendo a maioria

12 Registro de batismo da escrava Lucrécia na igreja de Nossa Senhora da Conceição das Campinas, 16 maio 1830, AEL, FPE, rolo 18.

13 Registro de batismo da escrava Maria na igreja de Nossa Senhora da Conceição das Campinas, 11 maio 1809, AEL, FPE, rolo 18. 
Artigos

dos rebeldes proveniente do Congo norte, com uma participação minoritária de escravos do sul de Angola. Como a grande maioria dos rebeldes de 1832 chegou nessas terras entre 1815 e 1820, suas procedências já refletiram as alterações gerais das correntes do tráfico e do próprio perfil demográfico de Campinas. Assim, percebe-se que nas três primeiras décadas do século XIX os fluxos do tráfico atlântico direcionadas para Campinas favoreceram a reunião de gente proveniente de uma mesma grande área da África, facilitando a identificação cultural e a construção de pontes para a formação de movimentos coletivos.

Também os censos populacionais representaram uma importante fonte para a tarefa de construção do cenário que envolveu a trajetória dos rebeldes de 1832. Se com os inventários pude configurar um contexto mais amplo sobre a população cativa em Campinas, com os censos populacionais foi possível olhar para as 15 propriedades com uma lupa de aumento ainda mais poderosa. Isto é, por meio dos censos pude conhecer melhor a própria história das fazendas em que os rebeldes habitavam. Os censos nos permitiram, por exemplo, identificar o momento em que essas propriedades foram criadas, com a chegada de seus fundadores (e de suas famílias) à Campinas no final do século XVIII e primeiros anos do XIX.

Desde o expressivo aumento do preço do açúcar no mercado mundial, decorrente, entre outras coisas, do declínio da produção haitiana (devido às instabilidades trazidas pela insurreição escrava que levou à independência daquele país), Campinas viu suas terras serem tomadas pelas plantações de cana e sua população crescer significativamente. Os proprietários com cativos envolvidos em 1832 prosperaram ao longo dos anos em que viveram em Campinas, contribuindo para a própria transformação do cenário local, comprando escravos africanos e expandindo suas produções agrícolas. No ano de 1832, todos eles já possuíam mais de duas dezenas de cativos, sendo que alguns estavam entre as maiores fortunas da cidade, com mais de uma centena de escravos e diversas fazendas produtoras de cana-de-açúcar. Dentre os proprietários que tiveram cativos envolvidos no plano de insurreição, aquele com menos posses no começo da década de 1830 tinha 21 cativos, enquanto que o mais afortunado deles tinha perto de cinco centenas de escravos.

Os censos populacionais foram fundamentais ainda na identificação do perfil demográfico dos cativos moradores das propriedades citadas na trama de 1832. De fato, foram com os dados dos censos que pude, entre outras coisas, comparar a situação matrimonial dos rebeldes com aquela da população escravizada que vivia nas 15 propriedades citadas no plano de insurreição. Apesar desse tipo de informação aparecer nos inventários post-mortem, nem sempre ela se apresenta de forma sistemática, diferentemente do caso dos censos populacionais em que, ano após ano, esse tipo de dado vinha registrado. A comparação, nesse sentido, permitiu reconhecer que a porcentagem de cativos casados envolvidos na trama de 1832 era bastante significativa. Se na média geral das fazendas os casados e viúvos representavam $23 \%$ da população escravizada, no plano de insurreição esse número é de 38\%. Foi fundamental perceber ainda que entre as lideranças do plano, esse número chegava a 57\% do total (PIROLA, 2011, p.107-108). Tais informações nos permitiram dialogar com parte da historiografia atual que tende a ver na conquista de um casamento e na formação da família escrava um processo estrutural de estabelecimento de paz nas senzalas. No caso da revolta de Campinas, ocorrida em 1832, essa tese esteve longe de ser confirmada. De fato, muitos dos rebeldes não só eram casados como ainda mantinham laços de parentesco ritual (compadrio) com diversos outros escravos - ponte fundamental para ligar as 15 senzalas da trama de 1832. Tal constatação, porém, só foi possível de ser feita graças ao procedimento de comparar as características dos rebeldes com o cenário maior em que eles estavam inseridos. Isto é, foi justamente a ampliação da análise para além dos envolvidos em 1832 que permitiu dimensionar suas características fundamentais e avançar no debate a respeito da relação entre formação de famílias escravas e rebeldia.

Já os registros eclesiásticos tiveram papel importante no trabalho de delinear um quadro mais geral das relações de parentesco escravo entre as 15 propriedades citadas em 1832. Se, por um lado, a busca individualizada dos rebeldes nos registros de batismo e casamento da Igreja Matriz de Campinas revelou informações fundamentais sobre suas trajetórias, por outro, uma análise ampliada de todos os registros das 15 propriedades ajudou a mostrar que as relações entre os escravos ultrapassavam as cercas das fazendas já há muito tempo. Através dessa pesquisa foi possível perceber, por exemplo, certos padrões na conformação de relações de compadrio ligando os cativos de diversas propriedades inseridas na trama rebelde. De maneira geral, os cativos dessas 15 propriedades estabeleciam relações de compadrio dentro da fazenda em que viviam, mas adotavam também certas fazendas como as 
preferidas para o estabelecimento de relações de parentesco ritual. No caso das fazendas de Floriano de Camargo Penteado, por exemplo, os escravos tinham como primeira escolha dos padrinhos de seus filhos outros cativos pertencentes ao mesmo senhor, mas arregimentavam também com grande frequência parceiros nas propriedades de Ana de Campos. A propriedade dessa senhora ficava geograficamente próxima às fazendas de Floriano de Camargo, tendo contribuído para o plano de insurreição de 1832 com o segundo maior número de cativos. Assim, foi cruzando as informações de todos os registros eclesiásticos dos senhores citados no processo-crime que conseguimos notar que várias das fazendas da revolta estavam ligadas por meio desses laços de parentesco, criando uma comunidade de senzalas que esteve na base da organização do plano de insurreição.

\section{Considerações Finais}

A utilização dos métodos da micro história e da biografia nas pesquisas sobre a escravidão no Brasil tem mostrado seu vigor por meio da publicação anual de diversos artigos e livros. Mesmo com os vários desafios que esse método impõe à realização da pesquisa histórica e à construção da narrativa, os resultados que dele pode se obter têm incentivado muitos historiadores a se aventurarem nesse campo. Ao longo deste texto busquei demonstrar alguns dos problemas que o método implica para o trabalho do historiador e algumas das soluções que encontrei ao procurar reconstruir a trajetória dos escravos envolvidos no plano de insurreição de 1832 em Campinas. O processo de ligação nominativa de fontes e a busca por reconstruir o cenário em que viveram os rebeldes antes da organização do plano foram os dois principais caminhos trilhados por meu trabalho. A intenção foi justamente a de criar uma base para cruzar análises de trajetórias particulares com um contexto mais geral e, a partir daí, tirar conclusões para serem debatidas com a bibliografia. Difícil dizer sobre as perspectivas futuras da biografia e micro história para o estudo da escravidão no Brasil. Contudo, fato é que até agora ela tem trazido novas perspectivas para fomentar o debate acadêmico.

\section{Fontes Manuscritas}

\section{Centro de Memória - Unicamp (CMU)}

Inventários Post-mortem para os anos de 1801 - 1835: pesquisa sistemática.

\section{Arquivo Edgard Leuenroth (AEL)}

Livro de Batizados de escravos da Igreja de Nossa Senhora da Conceição das Campinas, 1797-1835.

Livro de Casamentos de escravos da Igreja de Nossa Senhora da Conceição das Campinas, 1775-1835.

Lista de Habitantes - Levantamentos Populacionais da Vila de São Carlos (Campinas), 1806-1829.

Maços de População, Caixa 24-24, Anos de 1792 a 1797.

\section{Arquivo do Estado de São Paulo (AESP)}

Correspondência dos Capitães Generais 1721-1822, Vila de São Carlos (Campinas).

Ofícios Diversos de Campinas 1822-1835, Anos pesquisados 1822 até 1832.

\section{Referências}

DAVIS, Natalie Zemon. O retorno de Martin Guerre. Rio de Janeiro: Paz e Terra, 1987. . Nas margens: três mulheres do século XVII. São Paulo: Companhia das Letras, 1997.

FRANK, Zephyr L. Dutra's world: wealth and family in nineteenth-century Rio de Janeiro. Albuquerque: Editora da Universidade de New Mexico, 2004. 
Artigos

FURTADO, Júnia Ferreira. Chica da Silva e o contador dos diamantes: o outro lado do mito. São Paulo: Companhia das Letras, 2003.

GINZBURG, Carlo. O queijo e os vermes: o cotidiano e as ideias de um moleiro perseguido pela Inquisição. São Paulo: Companhia das Letras, 1987.

GRAHAM, Sandra Lauderdale. Caetana diz não: histórias de mulheres da sociedade escravista brasileira. São Paulo: Companhia das Letras, 2005.

LADURIE, Emmanuel Le Roy. Montaillou, povoado occitânico de 1294 a 1324. São Paulo: Companhia das Letras, 1997.

LEVI, Giovanni. A herança imaterial: trajetória de um exorcista no Piemonte do século XVII. Rio de Janeiro: Civilização Brasileira, 2000.

MACHADO, Maria Helena. Corpo, Gênero e Identidade no Limiar da Abolição: a história de Benedicta Maria Albina da Ilha ou Ovídia, escrava (sudeste, 1880). Revista Afro-Ásia, v. 42, UFBA (Bahia), 2010, p. 157-193.

QUEIRÓS, Suely Robles Reis de. Escravidão negra em São Paulo: um estudo das tensões provocadas pelo escravismo no século XIX. Rio de Janeiro: José Olympio, 1977.

REIS, João José \& GOMES, Flávio dos Santos \& CARVALHO, Marcos. O alufá Rufino: tráfico, escravidão e liberdade no atlântico (1822-1853). São Paulo: Companhia das Letras, 2010.

REIS, João José. Domingos Sodré, um sacerdote africano: escravidão, liberdade e candomblé na Bahia do século XIX. São Paulo: Companhia das Letras, 2008.

SWEET, James H. Domingos Alvares: african healing, and the intelectual history of the Atlantic World. Chapel Hill: The University of North Carolina Press, 2011.

XAVIER, Regina Célia. Religiosidade e escravidão, século XIX: mestre Tito. Porto Alegre: Editora da UFRGS, 2008. 